\title{
Study on the microstructure of the cement modified expansive soil
}

\author{
Xiaogang XUE ${ }^{1, a}$, Qiqi ZHANG ${ }^{2, b}$ and Zhanfeng LIU $^{2, c}$ \\ ${ }^{1}$ China Airport Construction Group Corporation of CAAC Northwest Branch, Shaanxi Xi'an 710075, \\ China; \\ ${ }^{2}$ Department of Geology, State Key Laboratory of Continental Dynamics, Northwest University, \\ Xi'an 710069, China. \\ a2577949578@qq.com, ${ }^{\text {b3132762958@qq.com, }{ }^{\mathrm{c}} 1149509012 @ q q . c o m}$
}

Keywords: Expansive soil; Cement improvement; Microstructure

\begin{abstract}
In this paper, the microstructure of cement modified expansive soil was studied, and the variation of the structure parameters with the change of cement content was analyzed. The results show that the equivalent diameter of structure unit larger body content is more, the more the amount of cement, porosity, small structure unit is relatively reduced, reducing the fractal dimension of soil particles; The specimen structure element has a directional effect at located in 90 degrees. The changes of physical and mechanical properties of the samples are closely related to their microstructural characteristics.
\end{abstract}

\section{Introduction}

Expansive soil is highly plastic clay which has fractured and significant swelling and shrinkage characteristics of dehydration, especially sensitive to water. When expansive soil is used as filler, it needs to be improved. With the cement improving, different cement content has different influence on physical and mechanical properties of expansive soil[1]. A large number of studies show that the microstructure of soil affects the engineering properties of the soil to a great extent. Jiang Mingjing studied the shear zone and the soil around the microstructure, provides the basis for the theory of progressive failure of soil[2]. By using the basic principles of computer image processing, Shi Bin explored the simple analytical method of the microstructure of cohesive soil[3]. Studies have shown that small changes in water content can cause the occurrence of significant changes in expansive soil engineering properties[4]. Slump caused by the slope generated climate change, instability Examples abound [5]. Based on the previous research results, it is found that the research on the microstructure of loess has been a way to reveal the change of engineering properties of expansive soil. At the same time, the previous studies on the microstructure of the modified expansive soil are less. Therefore, in this paper, the quantitative parameters of the microstructure of the samples were extracted by the image processing system for the quantitative treatment of different cement content of SEM scanning electron microscope. The quantitative parameters of the microstructure of the samples were extracted. Through the analysis of the quantitative parameters, to provide quantitative basis for the reason of the change of the physical and mechanical properties of soil. 


\section{The preparation of samples}

The samples are taken from expansive soil, and the sampling site is An'kang city. The pore is more developed, the structure is loose, and the soil is more uniform. The compression coefficient is between 0.43 and 0.21 , which belongs to the medium compression expansive soil, that has the characteristics of collapsible, and has low lateral compressive strength. Its physical index is shown in table 1. The cement used in the experiment is the composite Portland cement PC 32.5.

The experiment was carried out in strict accordance with the "standard of geotechnical test method" (GB/T 50123 - 1999). Cement improved soil volume was 0\%, 2\%, 4\% and 6\% respectively. Heavy compaction test using CSK-V1 type multifunctional electric compaction instrument. Make the moisture content of the soil sample for optimum moisture content, compaction coefficient $\eta=0.95$. After maintenance $14 \mathrm{~d}$ under standard condition, the consolidation, direct shear and scanning electron microscope tests were carried out on the soil samples. Scanning electron microscope test sample is the smallest part of the middle of the soil sample and cut into $1 \mathrm{~mm} *$ $1 \mathrm{~mm} * 2 \mathrm{~mm}$ rectangular. After the surface is plated with a scanning electron microscope, the SEM image is obtained.

Table 1 Basic physical properties of expansive soil

\begin{tabular}{ccccccccc}
\hline $\begin{array}{c}\text { Dry } \\
\text { density } \\
\left(\mathrm{g} \cdot \mathrm{cm}^{3}\right)\end{array}$ & $\begin{array}{c}\text { Mois } \\
\text {-ture } \\
(\%)\end{array}$ & $\begin{array}{c}\text { Severe } \\
\left(\mathrm{kN} \cdot \mathrm{m}^{-3}\right)\end{array}$ & $\begin{array}{c}\text { Porosi } \\
\text {-ty } \\
\text { ratio }\end{array}$ & $\begin{array}{c}\text { Satur } \\
\text { ation } \\
(\%)\end{array}$ & $\begin{array}{c}\text { Cohesi } \\
\text {-on } \\
(\mathrm{kPa})\end{array}$ & $\begin{array}{c}\text { Angle of } \\
\text { internal } \\
\text { friction } \\
\left({ }^{\circ}\right)\end{array}$ & $\begin{array}{c}\text { The average } \\
\text { degree of free } \\
\text { expansion } \\
(\%)\end{array}$ & $\begin{array}{c}\text { Turgid } \\
\text {-ity }\end{array}$ \\
\hline 1.67 & 13 & 19.8 & 0.499 & 61.2 & 168.0 & 20.5 & 47 & low \\
\hline
\end{tabular}

\section{Microstructure analysis of samples}

\subsection{Qualitative analysis of microstructure}

Scanning electron microscope (SEM) is an instrument to observe the microstructure of soil body. It is mainly focused on the electromagnetic lens focusing on the two electrons generated in the surface of the sample to form the microscopic image of the surface of the sample. This test uses the instrument for the Czech FEI company's Quanta FEI 400 FEG environment scanning electron microscope system.

The micro structure of soil is the size, shape and mutual arrangement of soil particles, especially the case of mutual connection. $0 \%$ clay materials in expansive soil cement is continuous, directional distribution, a cluster shape, pore shape irregular, micropores, dense structure, structure types can be classified into matrix structure. The mixing of cement can change the size and the connection mode of the soil particles. Added cement, as a result of the hydration reaction of cement, the soil particle cement, aggregation degree increased, large particles to form the framework, small particles attached to the uneven surface of larger particles, since link, contact with unit cohesion, the structure type for the skeleton. The mixing of cement can change the size and the connection mode of the soil particles. The cement content is $2 \%$ (b1), cement content is $4 \%$ (c1) of the SEM photos can be seen, the cement added, as a result of the hydration reaction of cement, the soil particle cement, aggregation degree increased, large particles to form the framework, small particles attached to the uneven surface of larger particles, since link, contact with unit cohesion, the structure type for the skeleton. The cement content is 6\% (d1) of SEM shows that the cement content increases to $6 \%$, the state of connection between soil particles changed dramatically, pores 
appeared obvious hydrated calcium silicate and radial fibrous, distribution on the particle surface or around connecting particles, forming structure unit for the larger body, granular structure. (a2,b2,c2, $\mathrm{d} 2)$ is $(\mathrm{a} 1, \mathrm{~b} 1, \mathrm{c} 1, \mathrm{~d} 1)$ in the threshold of $120,125,113,135$ under the black and white photographs,

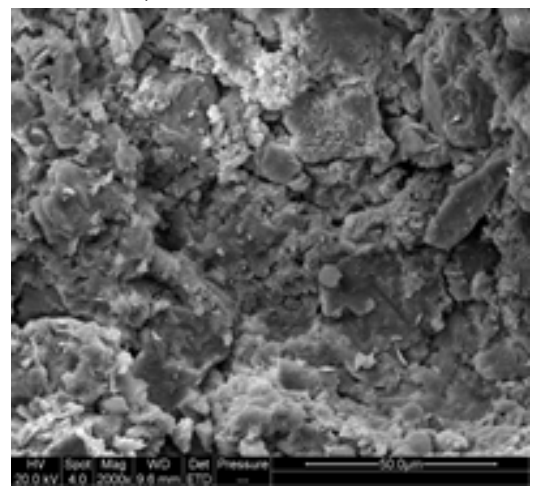

al Cement parameter $0 \%$

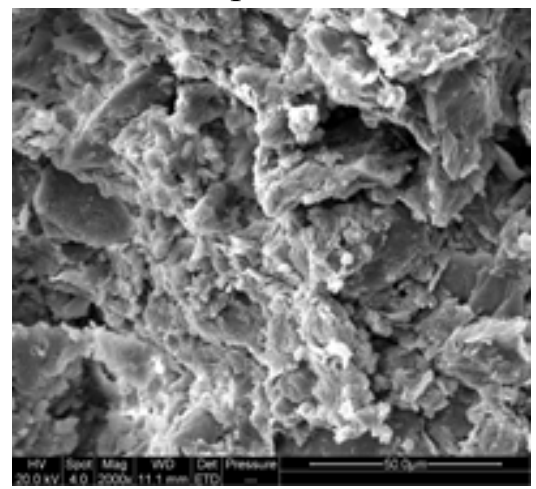

c1 Cement parameter $4 \%$

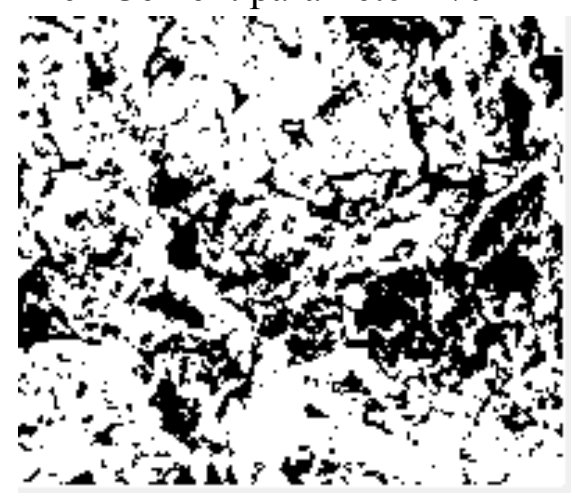

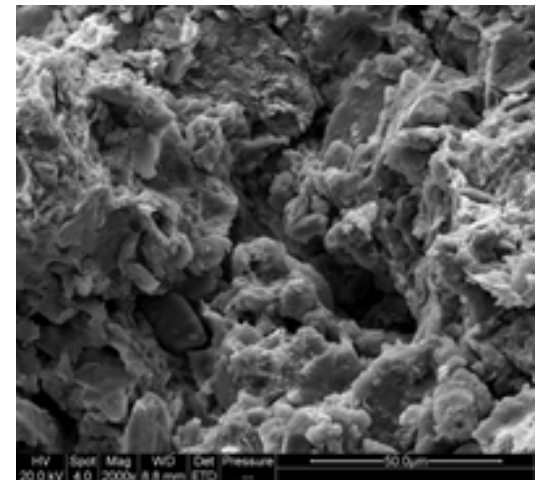

b1 Cement parameter $2 \%$

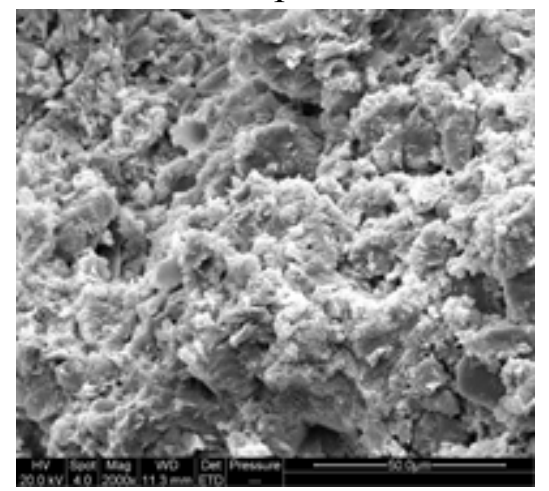

d1 Cement parameter $6 \%$

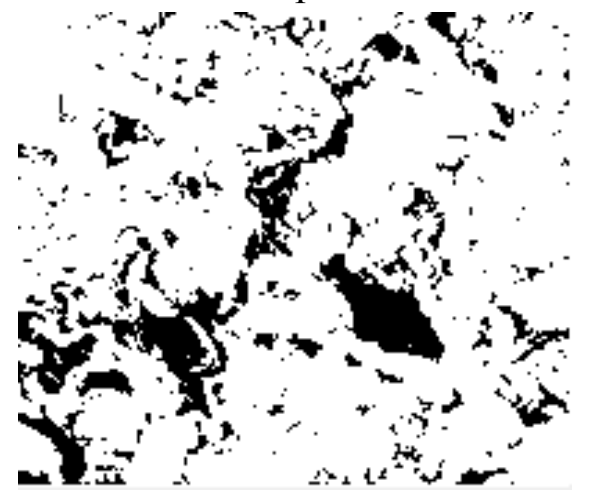

a2 Cement parameter 0\%（threshold $=120 ）$ b2 Cement parameter $0 \%($ threshold $=125$ )
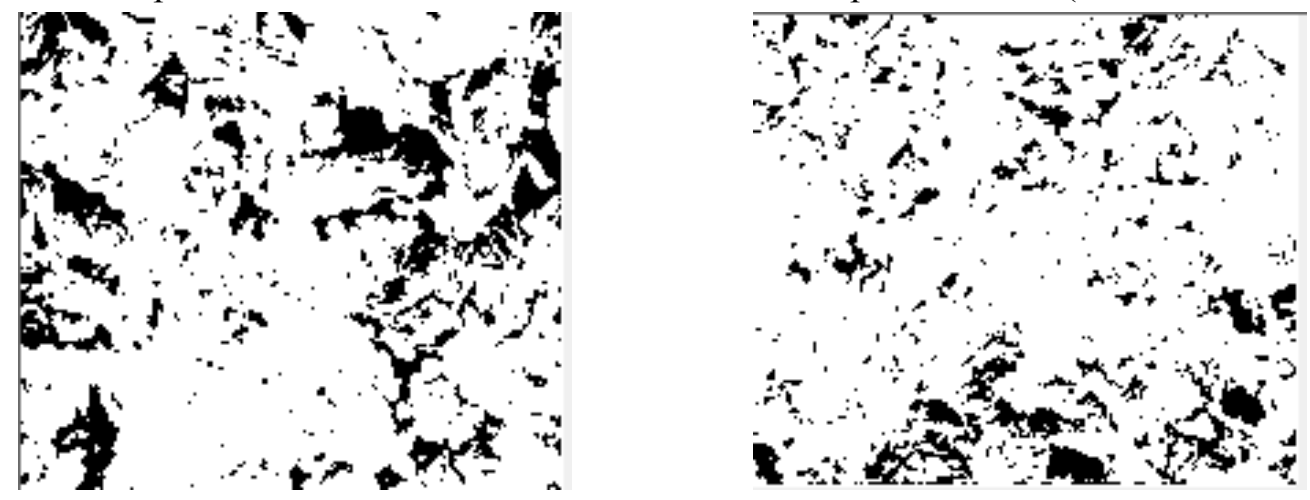

c2 Cement parameter 0\%（threshold $=113 ） \mathrm{~d} 2$ Cement parameter $0 \% （$ threshold $=135$ ）

Fig.1 SEM images of modified soil by zooming 2000 times 
which represent the black part of the pore, white part of the particle.

\subsection{Quantitative analysis of microstructure}

Scanning electron microscope photographs that the sample is magnified 2000 times are binarized, then convert to black and white photos. The best threshold value is the standard of the pore and particle morphology in the photo reaction. The Scanning electron microscope photographs that has been binarized can be extracted to a lot of improved soil porosity and particle size, arrangement characteristics, orientation, roundness and other structural parameters. In this paper, two pore structure parameters(plane porosity and directional frequency) and two particle structure parameters(equivalent diameter and fractal dimension) are chosen as the quantitative parameters for the study of microstructure.

3.2.1 Quantitative evaluation of structural unit size and morphological characters

(1)The equivalent diameter $\mathrm{D}$ is equivalent with the equal area circle diameter of soil particles, $\mathrm{D}=(4 \mathrm{~A} / \pi)^{1 / 2}$, where $\mathrm{A}$ is the actual area of soil particles.

(2) The plane porosity is the pore area / (particle area + pore area), $=\mathrm{A} /(\mathrm{A} 1+\mathrm{A}), \mathrm{A} 1$ is the particle size.

Table 2 is the results of grain size analysis for structural units. Table 3 is the results of plane porosity. As can be seen from table 2 equivalent diameter $\mathrm{D}$ of element soil element is mainly concentrated in the $<2 \mu \mathrm{m}$ of this interval. The equivalent diameter of the element is larger and mainly concentrate in $2 \sim 5 \mu \mathrm{m}, 5 \sim 10 \mu \mathrm{m}$ these two ranges after adding cement. And the particle size range of $>10 \mu \mathrm{m}$ followed. With the increase of cement content, reduction of structural units in the grain size range of $<2 \mu \mathrm{m}$ and $2 \sim 5 \mu \mathrm{m}$ and the structure units of $5 \sim 10 \mu \mathrm{m}$ and $>10 \mu \mathrm{m}$ diameter range increased. This shows that the equivalent diameter of the particles has a tendency to become larger and larger. The plane porosity reaction is tight of samples. With the increase of cement content, the area of the particles increases, the area of the pores decreases, and the unit of the structure becomes more and more compact( Can be seen from the table 3 ). The reasons of these changes is a product of soil and cement reaction to cementation between the particles, the new generation of biomass and constantly filled into large pores, aggregation structure unit continuously enhanced, large particles increased, the pore area decreased.This is consistent with the direct observation of the scanning electron microscope.

Table 2 Results of microstructure granularmetricanalysis of samples

\begin{tabular}{|c|c|c|c|c|c|}
\hline \multirow{2}{*}{$\begin{array}{c}\text { Cement } \\
\text { parameter } / \%\end{array}$} & \multicolumn{5}{|c|}{ Equivalent diameter $\mathrm{d} / \mu \mathrm{m}$} \\
\hline & \multicolumn{2}{|l|}{$<2$} & $2 \sim 5$ & $5 \sim 10$ & $>10$ \\
\hline 0 & \multicolumn{2}{|l|}{65} & 10 & 15 & 10 \\
\hline 2 & \multicolumn{2}{|l|}{35.29} & 41.18 & 17.65 & 11.76 \\
\hline 4 & \multicolumn{2}{|l|}{7.69} & 38.46 & 38.46 & 15.38 \\
\hline 6 & \multicolumn{2}{|l|}{7.14} & 28.57 & 42.86 & 21.43 \\
\hline \multicolumn{6}{|c|}{ Table 3 Data and results of plane porosity of samples } \\
\hline $\begin{array}{c}\text { Cement } \\
\text { content/(\%) }\end{array}$ & Threshold & $\begin{array}{c}\text { Particle } \\
\text { area } / \mu \mathrm{m}^{2}\end{array}$ & $\begin{array}{c}\text { Voi d } \\
\text { area/ } / \mathrm{m}^{2}\end{array}$ & $\begin{array}{c}\text { total } \\
\text { area/ } / \mu \mathrm{m}^{2}\end{array}$ & $\begin{array}{c}\text { Plane } \\
\text { porosity/(\%) }\end{array}$ \\
\hline 0 & 120 & 5078.07 & 9414.72 & 14492.79 & 65 \\
\hline 2 & 125 & 4779.04 & 7556.17 & 12335.21 & 61 \\
\hline 4 & 113 & 6145.45 & 8184.35 & 14329.80 & 57 \\
\hline 6 & 135 & 6475.53 & 6475.53 & 12951.06 & 50 \\
\hline
\end{tabular}




\subsubsection{Pore orientation evaluation}

The orientation of evaluation by directional pore frequency $F(\alpha)[6]$, according to the directional measurement object angle (the angle between the long axis and horizontal direction), 180 degrees will be divided into $\mathrm{N}$ location, thus obtained the directional frequency of pores in I location. General $\mathrm{n}=10$, then

$$
\mathrm{F}(\alpha)=\mathrm{k}_{\mathrm{i}} / \mathrm{K} \times 100 \%
$$

$\mathrm{k}_{\mathrm{i}}$ is the number of measuring objects in the first $\mathrm{I}$ location of the directional corner, and $\mathrm{K}$ is the total number of the measured objects.

Figure 2 shows the directional frequency distribution histograms of different cement content sample pore. The directional frequency of the porosity of each sample is distributed in most angles. About 90 degree the location of the probability of greater distribution is showed that the samples have obvious orientation in this region. This is mainly because the samples were made by heavy compaction method, and under the action of vertical impact force soil particles and soil pores are rearranged cause the angle between the major axis of the structural unit and the $\mathrm{X}$ axis is more concentrated in the 90 degree range[7].

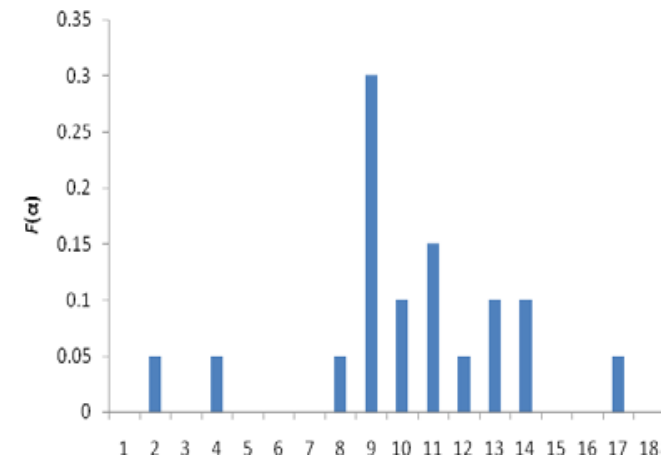

a3 Cement parameter $0 \%$

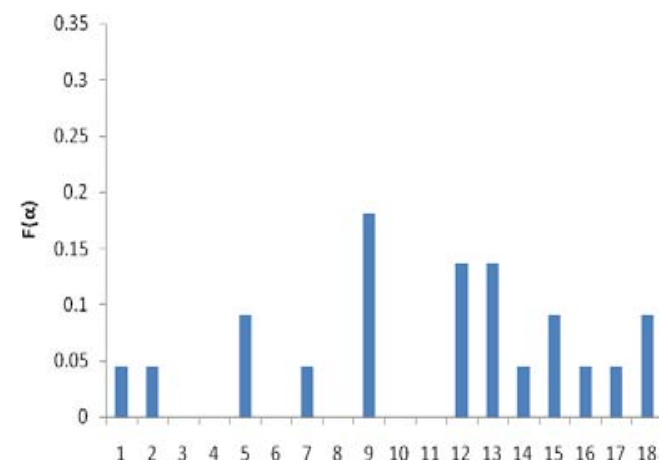

c3 Cement parameter $4 \%$

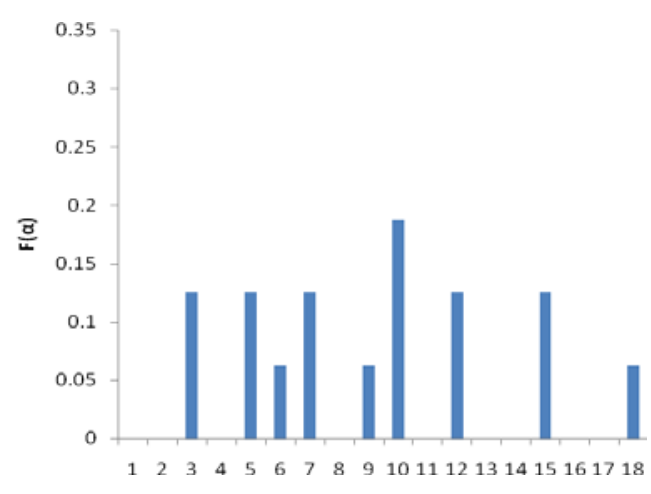

b3 Cement parameter $2 \%$

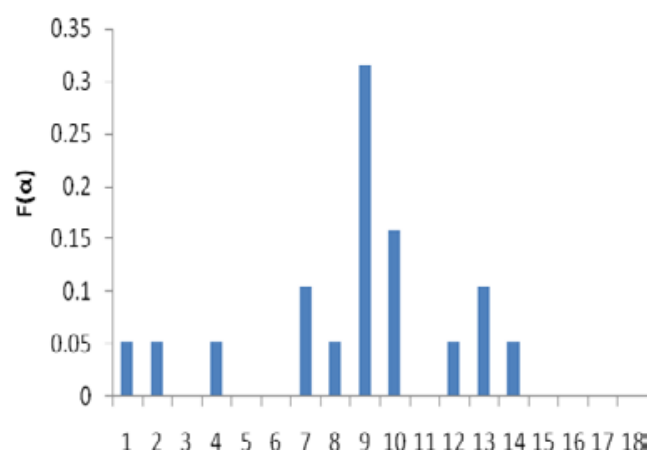

d3 Cement parameter $6 \%$

Fig.2 Histogram of orientation frequency of samples

\subsubsection{Fractal dimension of particle morphology}

The fractal dimension of particle shape is calculated by the area perimeter method[8]. Its basic principle is:

$\operatorname{Ln}\left(\mathrm{P}_{\mathrm{E}}\right)=(\mathrm{D} / 2) * \operatorname{Ln}(\mathrm{A})+\mathrm{C}$

$\mathrm{PE}$ : The equivalent circumference of an arbitrary polygon representing the soil particles.

A: Polygon equivalent area 


\section{C: constant \\ D: Fractal dimension of soil pore space[9]}

Through the equivalent area and perimeter of each soil particles are calculated, these data will be plotted in double logarithmic coordinates, then these data points are fitted to a straight line, the fractal dimension of particle morphology can be obtained by fitting a straight line of slope, the formula is as follows:

$$
\mathrm{D}=\mathrm{K} \times 2
$$

Fig. 3 is the relationship of the equivalent circumference and the equivalent area of the soil particles with different cement content. Table 4 is statistical table of sample amplification of 2000 times Ln (PE) Ln (A) linear relationship and fractal dimension. Can be seen from the table 4 that correlationcoefficient is greater than 0.962.So it can be used to study the fractal characteristics of particle morphology. The fractal dimension of soil particles is between 1-2. With the increase of cement content the fractal dimension of particles decreases. The reason for this change is that after the action of cement and soil water the precipitation of $\mathrm{Ca} 2+$ and the soil particles surface of $\mathrm{K}+$, $\mathrm{Na}+$ ion exchange, adsorption, and so on a series of reactions cause that the water film becomes thin, so that a large number of soil particles aggregate into clusters, and at the same time, a large number of $\mathrm{Ca} 2+$ and $\mathrm{SiO} 2$ and $\mathrm{A} 12 \mathrm{O} 3$ in the soil were separated into chemical reactions to form a stable fibrous crystalline mineral. $\mathrm{Ca}(\mathrm{OH}) 2$ produced by hydration of cement not only has strong adsorption, which makes the soil aggregate more closely combined, chain shaped structure formed of cement and soil particles, soil particles are filled in pores, but also is constantly with the air in the $\mathrm{CO} 2$ and $\mathrm{H} 2 \mathrm{CO} 3$ hydrolysis of the formation of the $\mathrm{CO} 2$ reaction to generate $\mathrm{CaCO} 3$, which make the soil particles to cement the formation of coarse grain. These reactions increase the agglomeration of the soil particles. Many small particles are bonded together, and the edges of the soil particles tend to be regular and round, so the fractal dimension of the particle shape becomes smaller.

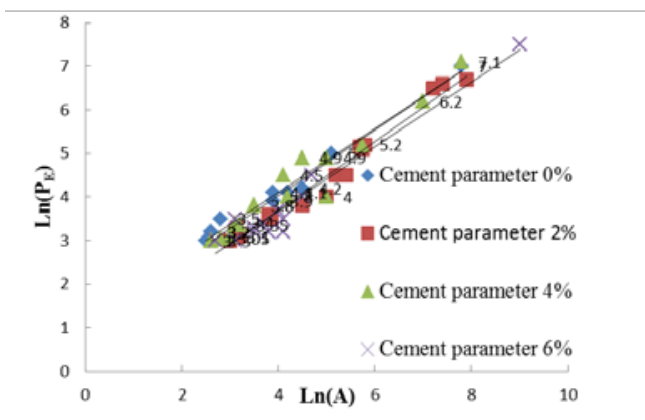

Fig. $3 \operatorname{Ln}\left(\mathrm{P}_{\mathrm{E}}\right)-\operatorname{Ln}(\mathrm{A})$ graph of samples 
Table 4 Linear relationship and fractal dimension of $\ln \left(\mathrm{P}_{E}\right)-\ln (\mathrm{A})$

\begin{tabular}{|c|c|c|c|c|}
\hline $\begin{array}{c}\text { Cement } \\
\text { content/(\%) }\end{array}$ & linear equations & $\begin{array}{c}R^{2} \text { correlation } \\
\text { coefficient }\end{array}$ & Rake K & $\begin{array}{c}\text { fractal } \\
\text { dimension } \\
\text { D }\end{array}$ \\
\hline 0 & $\ln \left(\mathrm{P}_{E}\right)=0.777 \ln (\mathrm{A})+0.707$ & 0.977 & 0.777 & 1.554 \\
\hline 2 & $\ln \left(\mathrm{P}_{E}\right)=0.747 \ln (\mathrm{A})+0.705$ & 0.991 & 0.747 & 1.494 \\
\hline 4 & $\ln \left(\mathrm{P}_{E}\right)=0.727 \ln (\mathrm{A})+0.970$ & 0.962 & 0.727 & 1.454 \\
\hline 6 & $\ln \left(\mathrm{P}_{E}\right)=0.713 \ln (\mathrm{A})+0.991$ & 0.964 & .0713 & 1.426 \\
\hline \multicolumn{5}{|c|}{ Table 5 Physical and mechanical test results of the modified soil } \\
\hline $\begin{array}{c}\text { Cement } \\
\text { content/(\%) }\end{array}$ & $\begin{array}{c}\text { optimum water } \\
\text { content }\end{array}$ & $\begin{array}{l}\text { maximum dry } \\
\text { density }\end{array}$ & $\mathrm{c} / \mathrm{kpa}$ & $\varphi /\left(^{\circ}\right)$ \\
\hline 0 & 12.81 & 1.84 & 93.80 & 29.77 \\
\hline 2 & 13.14 & 1.73 & 234.60 & 38.41 \\
\hline 4 & 13.89 & 1.71 & 249.10 & 40.56 \\
\hline 6 & 14.76 & 1.68 & 269.30 & 41.92 \\
\hline
\end{tabular}

4. Analysis on effect of expansive soil improvement

It can be seen from table 5 that with cement content increases the optimum water content increases and the maximum dry density decreases. The optimum water content increases because of after the cement hydration reaction the large pore is reduced and the increase of the small pore leads to the enhancement of the capillary action, and the water holding capacity increases. The greater the cement content, the more water is absorbed by the cement, the stronger the capillary effect, the real-time soil moisture is not easy to discharge, so the optimal water content increases with the increase of cement content. After the chemical reaction happened between soil and cement, the new biomass constantly filled into large pores. The soil particles aggregate to form aggregates between soil particles have more surface to surface contact, edge, and small particles increased the friction resistance When moving particles increases, hindered the soil particles approach each other in the compaction process. The hammer used in real time to overcome the friction power increased, the effective compaction power decreased, so the maximum dry density decreases with the increase of cement content.

The cohesion and internal friction angle of loess are increased by the addition of cement. Cohesion is mainly determined by the van Edward force, Coulomb force, cementation force and other physical and chemical effects of the particles. After the cement is added to the loess, the crystalline substance is continuously formed, and the bonding force between the particles is produced. And the cement particle is fine, the van Edward force and Coulomb force between the particles are large, which makes the particles further bond, and the cohesive force increases. The internal bite the friction is determined by the friction between the particles and the sliding friction force. The friction force is influenced by the density of the soil, the roundness and the strength of the particles. The sliding friction is related to mineral composition, particle shape, size and so on. After the addition of cement, due to the hydration reaction of cement, the porosity is decreased, and the gradation of loess is improved, the particle becomes more dense, so the internal friction angle increases. 


\section{Conclusion}

(1) Microstructure of samples is affected by cement content in improved soil. The structure type of the soil structure is the matrix structure, but when the cement content is $2 \%$ or $4 \%$, the structure type of the improved soil is the skeleton structure, and the structure type of the cement mixed with $6 \%$ is the aggregation structure. After cement incorporation, the connection status of soil particles changes significantly, the porosity decreased, the soil arrangement became close, and there were a lot of fibrous crystals in the pores, the more the cement content, the more obvious the changes.

(2) It can be seen from the quantitative analysis of microscopic structural units that with the increase of cement content, the larger the equivalent diameter of soil particles increased, the equivalent diameter of soil particles is relatively smaller, the pore area decreases, the particle size increases, the plane porosity decreases, and the fractal dimension of particle size decreases. This is because the sample is made by the heavy compaction method, and the directional angle is more concentrated in the 90 degree range.

(3) The physical and mechanical properties of loess are affected by the addition of cement. With the increase of cement content, the optimum water content increases and the maximum dry density decreases. At the same time, the cohesion and internal friction angle of loess are increased. Through the analysis of the microstructure characteristics of the sample, it can be used as the reason for the change of the physical and mechanical properties of the soil.

\section{Reference:}

[1] Ding J M, Wang Y H, Chen Z Y, et al. Water-destroyed disaster of expansive soil roadbed and it's forecast based on rough neural network[J]. Journal of Natural Disasters, 2006.

[2] Jiang M J, Shen Z J. Microscopic analysis of shear band in structured clay[J]. Chinese Jounal of Geotechnical Engineering, 1998.

[3] Wang Q, Dong H, Chen H, et al. MICROSTRUCTURAL CHARACTERISTIC OF CEMENT CONSOLIDATED SOFT SOIL[J]. Journal of Engineering Geology, 2007.

[4] YANG Guo-lin, DING Jia-ming. Model Test on Expansion and Shrinkage Deformation in Expansive Soil Roadbed[J]. China Journal of Highway \& Transport, 2006, 19(4):23-29.

[5] Yuan C, Zhou J, Yang M. TREATMENT OF EXPANSIVE SOIL SLOPES BESIDE HIGHWAYS[J]. Chinese Journal of Rock Mechanics \& Engineering, 2007.

[6] Liu Y, Wang Q. Quantitative study of microstructure characteristics of dredger fills after sediment[J]. Hydrogeology \& Engineering Geology, 2006, 33(3):124-128.

[7 ]Chen H, Wang Q. Analysis on microstructure of cement stabilized soil with different organic content[J]. Journal of Liaoning Technical University, 2009.

[8] HUANG Y, SUN X, WU Z Q. The fractal principle and application[M]. 2003

[9] Wang B J, Shi B, Liu Z B, et al. Fractal study on microstructure of clayey soil by GIS[J]. Chinese Jounal of Geotechnical Engineering, 2004. 